\title{
Radius Distal Uç Kırıkları: Kapandji Yöntemiyle İntrafokal Telleme ve Eksternal Fiksatör Tekniklerinin Prospektif Randomize Bir Çalışma ile Karşılaştırılması
}

\section{Radius Distal End Fractures: A Prospective Randomized Comparison of Intrafocal (Kapandji) Pinning Versus External Fixaton}

\author{
${ }^{1}$ Gökhan Ragip ULUSOY,${ }^{2}$ Michel VANCABEKE, ${ }^{2}$ Philippe BOUTÉ, ${ }^{2}$ Philippe PUTZ \\ ${ }^{1}$ Department of Orthopedics and Traumatology, Kafkas University, Kars, Turkey. \\ ${ }^{2}$ Department of Orthopedics and Traumatology, Université Libre de Bruxelles Brugmann Hospital, Brussels, Belgium.
}

Gökhan Ragıp Ulusoy: https://orcid.org/0000-0001-9804-1975

Michel Vancabeke: https://orcid.org/0000-0002-3413-2306

Philippe Bouté: https://orcid.org/0000-0002-9581-7245

Philippe Putz: https://orcid.org/0000-0002-7139-943X

\begin{abstract}
ÖZ
Amaç: Bu çalışmanın amacı, radius distal uç kırıklarında, intrafokal telleme (Kapandji) ve eksternal fiksatör (EF) tekniklerini, karşılaştırmak, radyolojik olarak redüksiyon'un kalitesi, fonksiyonel sonuçlar ve hastanın subjektif görüşlerini değerlendirmektir.

Materyal ve Metot: Yaș göz önüne alınmadan, birden fazla eklem içi kırık hattı olan çok parçalı kırıklar hariç, dorsale yer değiştirmiş radius distal uç kapalı kırığı ile başvuran 101 hasta değerlendirmeye alındı. 46 tanesi Kapandji, 55 tanesi EF ile tedavi edildiler.

Bulgular: Post-op 3. haftada, Kapandji yöntemiyle tedavi edilen hastalarda ağrı daha belirgindi $(\mathrm{p}=0,049)$. Hareket sınırları, ulnar deviasyon hariç, 6. haftada Kapandji yöntemiyle tedavi edilenlerde daha iyidi (fleksiyon için $\mathrm{p}<0,001$, ekstansiyon için $\mathrm{p}<0,001)$. Eklem içi kırıkların, cerrahi teknik göz önüne alınmadan, fonksiyonel ilerleme (Hareket açıklı̆̆ı, el sıkma kuvveti, günlük aktivite) üzerine etki etmediği görüldü. Sonuçlar 6 . ayda benzer bulundu. El sıkma kuvvetinin geri kazanılması intrafokal telleme için 6. hafta $(p=0,000)$ ve 3 . Ayda $(p=0,011)$ daha iyiydi.

Sonuç: Her iki teknik ile elde edilen sonuçlar birbirine benzerdir. Bizce konsolidasyon süresi düşünülenden daha uzun sürmektedir. Acaba immobilizasyon süresinin biraz daha arttırılması veya tellerin çıkarılmasının geciktirilmesi gerekmez mi? Ayrıca, kemik grefti, önemli dorsal çok parçalanma olan kırıklarda radyolojik sonuçları iyileştirecek bir çözüm olabilir.
\end{abstract}

Anahtar Kelimeler: Distal radius, eksternal fiksatör, kapandji, kırık, intrafokal telleme.

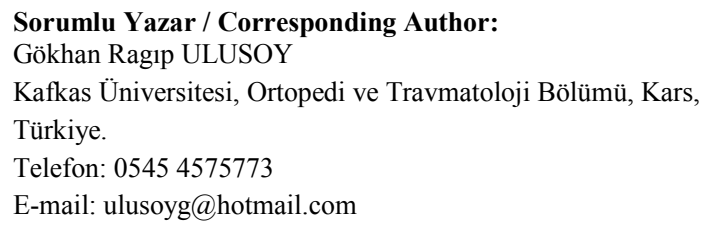

Atıf/ Cited: Ulusoy GR ve ark. Radius Distal Uç Kırıkları: Kapandji Yöntemiyle İntrafokal Telleme ve Eksternal Fiksatör Tekniklerinin Prospektif Randomize Bir Çalışma ile Karşılaştırılması. Online Türk Sağllk Bilimleri Dergisi 2020;5(1):106-116. doi: 10.26453/ otjhs. 483551

\section{ABSTRACT}

Objective: The aim of this study was to compare intrafocal wire (Kapandji) and external fixation techniques, to evaluate the quality of the reduction, functional outcomes and the subjective opinions in dorsally displaced fractures of the distal radius.

Materials and Methods: Regardless of age, 101 closed dorsally displaced distal radius fractures, except those with multiple intraarticular fracture line, were included in this study. 46 of them were treated with Kapandji and 55 with external fixator.

Results: At post-op 3rd week, pain was more evident $(p=0,049)$ in patients treated with Kapandji method. The range of motion, except for the patients with ulnar deviation, was better in patients treated with Kapandji at 6 weeks (flexion $p<0,001$, extension $p<0,001$ ). Regardless of surgical technique, intraarticular fractures do not affect functional progression (ROM, grip strength, daily activities). The results were similar at 6 months. The recovery of grip strength was better for intrafocal pinning at 6 weeks $(p=0,000)$ and 3 months $(p=0,011)$.

Conclusion: The results obtained with both techniques are similar. In our opinion, the consolidation period lasts longer than expected. It might be better to increase the immobilization time and delay the removal of the wires. In addition, bone grafting can be a solution to improve radiological outcomes for fractures with severe dorsal comminution.

Keywords: Distal radius, external fixator, kapandji, fracture, intrafocal pinning.

Yayın Bilgisi / Article Info:

Gönderi Tarihi/ Received: 15.11.2018

Kabul Tarihi/ Accepted: 02.07.2019

Online Yayın Tarihi/ Published: 31/03/2020 


\section{GíRiş}

Radius distal uç kırıkları çeşitlilikleri ve sıklıkları ile karakterizedirler. Erişkinlerde görülen kırıkların \%815'ini oluşturmaktadırlar. ${ }^{1}$

Yıllar önce bu kırıklar en sıradan kırıklar olarak görülüyordu ve genellikle kapalı redüksiyon ve alçı ile tedavi ediliyordu. Genellikle yaşlı kişilerde meydana gelmesi nedeniyle kötü sonuçlar kolaylıkla kabulleniliyordu. ${ }^{2}$ Zamanla bu kırıkların görülme sıklığının artması ve özellikle iş ve trafik kazaları nedeniyle genç ve aktif kişilerde görülmesi, yeni tekniklerin

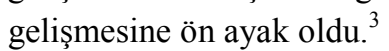

Radius distal uç kırıkları, artık sadece yaşlı osteoporotik kadınlarda görülen ve kötü fonksiyonel sonuçların kabul edildiği basit kırıklar olarak görülmemelidir.

Osteosentez tekniklerinin gelişmesi, cerrahlara daha etkili tedavi yöntemleri sundu. Perkütan yöntemler, özellikle Kapandji yöntemiyle intrafokal telleme tekniğinin ortaya çıkması ile modifiye olmaya başlad1. 20 seneden beri bu teknik etkinliğini kanıtladı fakat yine de bu teknik tellerin migrasyonu, tendon yaralanma riski ve radius'un k1salması gibi problemler nedeniyle eleştirildi. ${ }^{4}$ Eksternal fiksatör (EF)'un geliştirilmesi kırıkların distraksiyon ile redüksiyonuna olanak sağladı. Günümüzde, EF, komplikasyonlarının ve limitlerinin anlaşılmasıyla daha etkili kullanılır hale gelmiştir. ${ }^{5}$

Kapandji yöntemiyle intrafokal telleme ve EF, radius distal ucu dorsale deplase kırıklarında etkinliklerini kanıtlamışlardır. Bu çalışmanın amacı, bu iki tekniği prospektif randomize bir çalışma ile karşılaştırmak, radyolojik olarak redüksiyonun kalitesi, fonksiyonel sonuçlar ve hastanın subjektif görüşlerini değerlendirmektir.

\section{MATERYAL VE METOT}

1998'den 2000 yılına kadar, radius distal uç kırı̆ğ ile gelen 107 hasta Brugmann Üniversite Hastanesinde cerrahi olarak tedavi edilmişlerdir. Bu çalışma için ULB (Université Libre de Bruxelles) Brugmann Hastanesi etik kurulundan onay alındı (Tarih: 18/11/1997, Karar no: C.E.1997/36). Prospektif randomize bu çalışmada, EF ve Kapandji yöntemiyle intrafokal telleme olmak üzere iki ayrı teknik kullanildi.

Hastalardan 4 tanesinin tedavi tamamen sonlanmadan kontrole gelmeyi birakmaları ve dosyalardan 2 tanesinde yeterli veri olmaması nedeniyle 6 hasta çalışmadan çıkarıldı. Sonuç olarak 101 hasta çalışmaya dahil edildi. Yaş göz önüne alınmadan, birden fazla eklem içi kırık hattı olan çok parçalı kırıklar hariç, dorsale yer değiştirmiş radius distal uç kapalı kırı̆̆ı ile başvuran hastaların tümü bu çalışmaya dahil edildi.

Bütün kırıklar ameliyat öncesi çekilen anteroposterior ve lateral radyografik incelemeler ile Frykman ve Older sinıflandırma sistemlerine göre sinıflandirıldilar.

Cerrahi Teknik: Tedavi şekli, ameliyattan hemen önce kapalı zarf kura çekimiyle belirlendi. Kapandji yöntemiyle intrafokal telleme genel (30 vakada) veya lokorejyonal anestezi (16 vakada) altında, bütün asepsi kurallarına uyularak, turnike kullanılmadan, skopi altında gerçekleştirildi. 1 cm'lik cilt insizyonundan ve cilt altı yapılar uygun aletlerle ekarte edildikten sonra, 2 tane yivsiz tel intrafokal olarak gönderildi. Daha sonra teller $45^{\circ}$ eğildikten sonra bir motor yardımıyla karşı kortikale doğru itildi. Birinci tel dorsal yüzden, ikinci tel radial yüzden olmak üzere yerleştirildi. Teller daha sonra tendon katlarının hemen üstünden, cildin hemen altından bükülmeden kesildi. Cilt kesileri uygun materyel ile kapandıktan sonra dorsal bir alçı ateli kondu ve atel ortalama olarak 10 gün sonra çıkartıld1. Dikişler ameliyat sonrası 15. günde alındı, teller ise 6. hafta lokal anestezi altında çıkarıldı.

EF, genel anestezi (36 vakada) ve lokorejyonal anestezi (19 vakada) altında, turnike kullanılmadan, skopi altında gerçekleştirildi. İki pin, radial sinirin duyusal dalına zarar vermemek amaciyla, radial stiloid ucundan 4 parmak proksimalde diafiz seviyesinden kondu, daha sonra iki pin 2. metakarp diafiz seviyesinden gönderildi. Pinlerin diafize konması skopi altında yapıldı daha sonra bağlantı materyelleri pinlere ilave edilerek $20 \mathrm{~cm}$ 'lik metal çubuk ile bağlandı. Redüksiyon, başparmak ve 3 . parmak üzerinden uzunlamasına traksiyon yapılırken, aynı zamanda ön kol üzerinden kontr-traksiyon uyguland. $\mathrm{Bu}$ etap, karpal kemikler ile olan ligamanter bağlar sayesinde, fragmanların birbirinden ayrılmasını ve hizaya girmesini sağlamak amacı ile gerçekleştirildi. Cerrah, başparmak üzerinden traksiyona devam ederken, diğer el ile özellikle epifiz olmak üzere, fragmanlara şekil verildi. El bileğine uygun pozisyon verilerek eklem yüzlerinin normal eğimleri sağlandı. Eksternal fiksatör, el bileği palmar fleksiyon ve ulnar deviasyonda sabitlendi. Skopik kontrol redüksiyonun kalitesini değerlendirmek için kullanıldı. EF 3. hafta gevşetilerek el bileği nötral pozisyona getirildi, 6. hafta tamamen çıkartıldi.

Hastalar ameliyat sonrası sistematik olarak 1, 3, 6'ncı haftalar ve 3, 6'ncı aylarda kontrol için görül- 
dü. Hareket sınırları (fleksiyon, ekstansiyon, ulnar deviasyon, radial deviasyon) bir goniometre yard1mıyla ölçüldü. Ağrı, 0'dan 10'a kadar olan görsel cetvel yardımıyla değerlendirildi. El sıkma kuvveti ve başparmak-işaret parmağı sıkıştırma kuvveti Jamar tipi dinamometre ile ölçüldü.

Standart anteroposterior ve lateral grafiler hemen ameliyat sonrası (kırık taraf, sağlam taraf), daha sonra 1, 3, 6'ncı haftalar ve 3,6'ncı aylarda gerçekleştirildi. Palmar tilt, radial inklinasyon ve radioulnar indeks her filmde ölçüldü ve her hastanın normal değerlerini gösteren sağlam taraf grafisiyle karşılaştırıldı.

Tüm verler SPSS programına yüklendi. Verilerin dağılımı Kolmogorov-Smirnow testi ile yapıldı. Sayısal veriler normal dağılıma sahip olmadığında Mann Whitney U testi kullanıldı. Verilerin normal dağılıma sahip olması durumunda student-t testi kullanıldı. Anlamlılık düzeyi $\mathrm{p}<0,05$ olarak kabul edildi.

\section{BULGULAR}

101 hastadan, 46 tanesi Kapandji yöntemiyle intrafokal telleme ile 55 tanesi ise EF ile tedavi edildiler. Olguların 12 tanesi erkek, 89 tanesi kadındı (Tablo 1), ortalama yaş 70,2 (20 ile 98 arası) idi. Intrafokal telleme ile tedavi edilen 46 hastanın yaş ortalamas1 69,5 idi. Bu grubun 8 tanesi erkek (\% $17,4), 43$ tanesi sağ el dominant $(\% 93,5)$ ve 26 tanesinde dominant taraf kırıktı $(56,5)$. EF ile tedavi edilen 55 hastanın yaş ortalaması 70,7 olarak hesapland. Hastaların 4 tanesi erkek $(\% 7,3), 53$ tanesi sağ el dominant $(\% 96,4)$ ve 21 tanesinde $(\% 38,2)$ dominant taraf kıriktı.

A ğr $r$ : Ameliyat sonrası ağrı, 3. haftada, Kapandji yöntemiyle tedavi edilen hastalarda daha belirgindi ve iki teknik arasındaki değişiklik istatistiki olarak önemli idi $(\mathrm{p}=0,049)$.

Altıncı ayda iki teknik arasında belirgin bir fark kalmadı. 68 hasta tamamen ağrısız (Kapandji grubu 33 hasta, EF grubu 35 hasta) iken, 24 hasta (kapandji grubu 10 hasta, EF grubu 14 hasta) zaman zaman olan 10 üzerinden 2, 5 hasta (Kapandji grubu 2 hasta, EF grubu 3 hasta) zaman zaman olan 10 üzerinden 3 ve 4 hasta (Kapandji grubu 1 hasta, EF grubu 3 hasta) s1k sık olan 10 üzerinden 4 değerlerinde ağr1 bildirdiler. 6. ayda ağrı 18 hastada (\%50) ulnar, 6 hastada $(\% 16,6)$ dorsal, 5 hastada $(\% 13,8)$ radial, 5 hastada $(\% 13,8)$ başparmak seviyesinde, 2 hastada $(\% 5,5)$ el seviyesinde ve 1 hastada $(\% 2,8)$ diğer parmaklar seviyesinde idi.

Mobilite: Elde edilen sonuçlar cesaret verici oldu, çünkü eklem hareketleri iyi sınırlarda kaldı. Altıncı ayda ortalama değerler (Tablo 2), birbirine yakın bulundu. Hareket sınırları, ulnar deviasyon hariç, 6 . haftada Kapandji yöntemiyle tedavi edilenlerde daha iyidi (fleksiyon için $p<0,001$, ekstansiyon için $\mathrm{p}<0,001)$. Bu avantaj, 6. haftadan sonra devam etti, giderek azaldı ve 6 . ayda değişiklik artık istatistiki olarak önemli değildi (fleksiyon için $\mathrm{p}=0,062$, ekstansiyon için $\mathrm{p}=0,211$ ).

Radyolojik sonuçlar: Radial inklinasyon, palmar tilt ve radioulnar indeks değerleri ölçüldü (Tablo 3 ).

Radial inklinasyon: Radyolojik kriterlerin analizi radial inklinasyon açısının çok iyi değerlere geldiğini gösterdi. Bu değerlerin zaman içinde ilerlemesi, ortalama $2,8^{\circ}$ bir kayıp ile stabildi. Altıncı ayda iki teknik arasında istatistiki olarak belirgin bir farkl1lık yoktu.

Palmar tilt: Bunun düzeltilmesi radial inklinasyona göre daha başarısızdı ve ikincil yer değiştirme daha önemliydi. Ancak, gruplar arasında 6. ayda değişiklik istatistiki olarak önemli değildi.

Radioulnar indeks: Distal radioulnar indeks her iki grupta ilk başta kabul edilebilir değerlerde düzeltildi, fakat 3. aya kadar bir artma gözlendi. Artış Kapandji yöntemiyle tedavi edilen hastalarda daha anlamlıyd, fakat fark istatistiki olarak önemli değildi.

Ulnar Stiloid Kırı̆ğı: Olguların \%58'inde ulnar stiloid kırığı bulduk. Bunun için Frykman sınıflandırması kullanıldı. Bütün kırıklar, tedavi şekli göz önüne alınmadan, ulnar stiloid kırığının etkisini görmek amacıyla, değerlendirildi. Altınc1 ayda, ağrı, ulnar stiloid kırığı olan olgularda ortalama olarak $1,9^{\prime}$ du, kırık olmayan olgularda ortalama değer 1,5'di, fark istatistiksel olarak önemli değildi.

Eklem İçi Kırıklar: 101 olgunun 27'sinde ( \%26,7) eklem içi kırık söz konusuydu. EF grubunda 11 eklem içi kırık (Frykman sınıflandırmasına göre 3 tane tip 8, 6 tane tip 4, 2 tane tip 3, Older siniflamasina göre 11 tane tip 4), Kapandji grubunda 16 eklem içi kırık (Frykman sınıflamasına göre 4 tane tip 8, 2 tane tip 7, 6 tane tip 4, 4 tane tip 3, Older siniflamasına göre 16 tane tip 4) bulunmaktaydı (Tablo 4). Redüksüyon sonrası radyolojik kriterler kabul edilebilir sınırlardaydı ancak redüksiyon kaybı daha çabuktu.

Eklem içi krıklarda, cerrahi teknik göz önüne alınmadan, fonksiyonel ilerleme (hareket açıklığı, el sıkma kuvveti, günlük aktivite) üzerine etki görülmedi. Sonuçlar 6. ayda benzer bulundu. Eklem içi kırıklarda, radioulnar indeks EF ile daha iyi düzeltilmesine rağmen, 3 radyolojik kriteri içeren fark istatistiki olarak önemli değildi. 
Kuvvet: El ve başparmak-işaret parmağ 1 sıkma kuvveti, EF ile tedavi edilenlerde, EF'un 6. Hafta çıkarılması nedeniyle, 6. haftadan itibaren, intrafokal telleme ile tedavi edilenlerde 3. haftadan itibaren ölçüldü. El sıkma kuvvetinin geri kazanılması intrafokal telleme için 6 . hafta $(p=0,000)$ ve 3 . ayda $(0,011)$ daha iyiydi, fark istatistiksel olarak anlamlıydı, fakat 6 . ayda fark artık önemli değildi

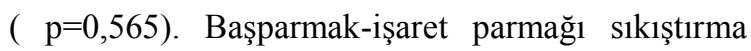
kuvveti, Kapandji lehine, istatistiksel olarak 6 . haftada farkliyd $1(p=0,001)$, fakat 3. ve 6. aylarda fark artık önemli değildi.

Komplikasyonlar: EF ile tedavi edilen grupta, 2'si kalıcı olmak üzere (metakarp veya radius hizasında sinir pin etrafina dolanır) 7 (\%13) tane radial sinir duyusal dalı tutulumu, 9 (\%16) yüzeysel enfeksiyon (pin etrafında basit süpürasyon şeklinde), değiştirilmeyi gerektiren 1 pin migrasyonu, 5 nöroalgodistrofi (\%9) bulduk. Herhangi bir tendon lezyonu ile karş1laşmadik.

Kapandji yöntemiyle tedavi edilen grupta, daha az komplikasyon oldu. $3(\% 6,5)$ tane tel migrasyonu görüldü, $2(\% 4)$ hastada radial sinir duyusal dalı tutulumuna benzer klinik belirtiler görüldü. $2(\% 4)$ hastada ekstensör pollisis longus rüptürü, ekstensör indisis proprius tendon transferi ile düzeltildi. $\mathrm{Bu}$ grupta $3(\% 6,5)$ tane nöroalgodistrofi bulundu.

\section{TARTIŞMA VE SONUÇ}

El bileğinin, eklem içi veya eklem dışı kırıklarının temel sorunu yanlış kaynama ile sonuçlanan ikincil yer değiştirmelerdir. Anatomik redüksiyon ve özellikle bu redüksiyonun, kaynama elde edilinceye kadar korunabilmesi cerrahların sıklıkla karş1 karşıya kaldıkları zorluklardan biridir.

Bizim serimizde, hareket aralığı, Kapandji yöntemiyle intrafokal telleme ile tedavi edilen hastalarda 6. haftada belirgin bir şekilde daha iyiydi, fakat bu avantaj eksternal fiksatör ile tedavi edilen hastalarda fiksatörün çıkarılmasından sonra az bir süre devam etti. Üçüncü haftada ağrının miktarı, intrafokal telleme ile tedavi edilen hastalarda çok daha fazla olduğu gözlendi, bunun nedeni, bize göre, erken mobilizasyon idi. 15 gün süreyle uygulanacak bir atel bu problemi çözebilir. Bazı yazarlar Kapandji tekniği uygulanan hastalarda daha iyi ağrı kontrolü için en az 6 hafta immobilizasyon önermektedir. ${ }^{6}$ İntrafokal telleme ile tedavi edilen 46 el bileğinden 33'ü (\%72) tamamen ağrısızdı. Bir başka seride bu oran $\% 84$ olarak bulunmaktadır. ${ }^{7}$ Eksternal fiksatörlü grupta bizim serimizde 55 el bileğinden 35'i (\%64) tamamen ağrısız iken literatürde bu oran bir seride $\% 67$ olarak bulunmaktadır. ${ }^{8}$ Radius distal uç kırığına eşlik eden ve genellikle psödoartroz ile sonuçlanan ulnar stiloid kırığı bizim serimizde literatürle uyumlu olarak \%58 oranında bulundu. ${ }^{9}$ Bazı yazarlara göre psödoartroz çok sık gelişmekte ve ulnar taraf ağrısının sebebi olmaktadır. ${ }^{10}$ Buna karşın, kapalı redüksiyon ve alçılı tespit ile tedavi edilen 109 kırık üzerinde yapılan bir çalışmada, ulnar stiloid kırığı olan grupta olmayanlara göre ulnar tarafta daha fazla ağrı olmadı $\breve{g ̆}_{1}$ gösterilmiştir. ${ }^{11} \mathrm{Bi}$ zim serimizde ulnar stiloid kırığının ağrı üzerinde herhangi bir etkisi olmamıştır. Literatür ile karşılaştırıldığında, ağrı ile ilgili sonuçlarımız intrafokal telleme ile tedavi edilen grupta, biraz daha kötü bulundu. Eğer ağrıyı belirleyici bir eleman olarak kabul edersek, hastaların 2/3'ü ağrıdan şikayet etmiyor veya rahatsız etmeyen hafif ağrıdan söz ediyorlardı. Fonksiyonel sonuçlar seriye göre değişkenlik göstermektedir. Eksternal fiksatör kullanılan bir seride, 1 y1l sonunda ortalama fleksiyon $80^{\circ}$, ekstansiyon $75^{\circ}$, radial deviasyon $10^{\circ}$, ulnar deviasyon $21^{\circ}$ olarak rapor edilmiştir. ${ }^{12}$ Bizim serimizde 6 ay sonunda bu değerler fleksiyon için $52^{\circ}$, ekstansiyon için $54^{\circ}$, ulnar deviasyon için $29^{\circ}$ ve radial deviasyon için $13^{\circ}$ olarak ölçüldü. Bizim kullandığımız teknik ister intrafokal telleme ister eksternal fiksatör olsun, elde edilen sonuçlar birbirine yakın bulundu.

Söz konusu, radyolojik kriterler olduğunda elde edilen sonuçlar, eksternal fiksatör kullanılan grupta biraz daha iyiydi fakat 6 ay sonunda fark istatistiksel olarak önemli değildi. Kapandji yöntemiyle elde edilen bu hiporedüksiyon fonksiyonel sonuçları bozmuyordu ve Delattre ve ark. ${ }^{13}$ tarafindan önerildiği gibi, dorsal tellerin açısını arttırarak bu sorun çözülebilirdi. Hareket ile ilgili çalışmalarda, Docquier ve ark., ${ }^{14}$ hiperkorreksiyon durumunda $\left(13^{\circ}\right.$ ila $\left.16^{\circ}\right)$, el bileğinin ekstansiyonunda kisitlılık meydana gelirken, hiporedüksiyon durumunda herhangi bir fleksiyon kısıtlılığı olmadığını göstermiştir. $\mathrm{Bu}$ da gösteriyorki deformasyonun fazla düzeltilmesindense az düzeltilmesi tercih edilmelidir. Kapandji yöntemiyle tedavi edilen grupta, dorsomedial fragmanı redükte eden üçüncü bir telin kullanılması radyolojik kriterlerde (özellikle radioulnar indeks) iyileşmeye sebep olabilir. Bizim serimizde, eksternal fiksatör ile tedavi edilen kırıklarda, en son elde edilen palmar tilt açısı 3,5 iken, literatürdeki diğer çalışmalarda $1^{\circ}$ ila $7^{\circ}$ arasında değişmektedir. ${ }^{7,15-18}$ Sagittal düzlemdeki redüksiyon kaybının en önemli olduğu dönem 3. haftadan sonra oldu. $\mathrm{Bu}$ dönem eksternal fiksatör ile uygulanan distraksiyonun gevşetildiği döneme denk gelmektedir. Distraksiyonun 
daha uzun korunması bu problemi ortadan kaldırabilirdi. Edwards ${ }^{19}$ ekternal fiksatörün kaldığ 8 hafta boyunca distraksiyon uygulamaktadır ve sadece 0 'dan 3 mm'ye kadar bir uzunluk kaybı bildirmektedir. En son ölçülen radial inklinasyon bizim serimizde $21^{\circ}$ bulundu, bu değer literatür ile uyumlu gözükmektedir. ${ }^{15,20}$ Yine eksternal fiksatör ile tedavi edilen grupta radioulnar indeks bizim serimizde $1,4 \mathrm{~mm}$ olarak bulundu. Bizim serimizde, olguların bir tanesinde, ilk redüksiyon tatminkar olmasına rağmen, 3 aya kadar devam eden bir ikincil yer değiştirme bulundu ve ölçülen değerler şöyleydi; radial inklinasyon $28^{\circ}$, palmar tilt $28^{\circ}$ ve radioulnar indeks $8 \mathrm{~mm}$. Söz konusu olan dorsal komminüsyon ile olan eklem içi bir kırıktı. Bu hasta daha sonra Darrach ameliyatı ile bazı şikayetlerinden kurtuldu. $\mathrm{Bu}$ ikincil yer değiştirme muhtemelen bir kemik defekti ve konsolidasyon kusuruna bağlıydı. Ameliyat öncesi ve sırasinda yapılacak filmlerin analizinin, literatürde de önerildiği gibi, uygulanacak tekniğe, sonuçları iyileştirebilecek diğer tekniklerin ilave edilmesine karar verilmesi için çok önemli olduğunu düşünüyoruz. ${ }^{21-23}$ Kapandji yöntemiyle tedavi edilen grupta elde edilen son radyolojik sonuçlar yine literatür ile uyumlu bulundu. ${ }^{24-25}$

Eksternal fiksasyon ikincil yer değiştirmeleri önlemek ve tatmin edici anatomik sonuçlar elde etmek için etkili bir metottur. ${ }^{26}$ Eksternal fiksatör ile iyi radyolojik sonuçlar elde edilebilir. Kapandji yöntemiyle tedavi edilen eklem içi kırıklarda da benzer sonuçlar elde edildi. İntrafokal telleme yönteminin, sınırlı olduğunu düşündüğümüz endikasyonları aslında oldukça geniş olarak karşımıza çıktı.

Altı ay sonunda, sağlam tarafa göre elde edilen el sıkma kuvveti eksternal fiksatör ile tedavi edilen grupta $\% 75$, Kapandji yöntemiyle tedavi edilen grupta \%71 bulundu. Literatürde, eksternal fiksatör için bulunan $\% 72$ değeri ile bizim sonuçlarımız benzerlik göstermektedir. ${ }^{27}$ Docquier ve ark.14'nın serisinde Kapandji yöntemiyle tedavi edilen 32 olgunun $\% 80$ 'i tatmin edici şekilde kuvveti geri kazanmıştır. Dorsal çok parçalanma varlığında elde edilen radyolojik sonuçlar daha kötüydü fakat fark istatistiksel olarak anlamlı değildi. Fonksiyonel sonuçlar dorsal çok parçalanma olan olgularda olmayanlara göre daha kötü değildi. Dorsal korteks çok parçalı ve kortikal defektli olgularda, greft ve anterior plak kullanılmasını önerebiliriz. Eksternal fiksatör ile tedavi edilen grupta görülen komplikasyon oranı daha fazlayd 1 : \%13' e karşı

\%40. Radial sinirin duysal dalının lezyonu eksternal fiksatör grubunda 7 iken Kapandji grubunda 2 bu- lundu. Bu risk, eksternal fiksatör için \%8 ile \%13 arasında bildirilmektedir. ${ }^{27,28}$ Özellikle radial seviyede yapılacak geniş deri insizyonu ve koruyucu bir materyel kullanılması pin konulması esnasında sinirin pin etrafına dolanmasını önleyecektir.

Eksternal fiksatör grubunda 9 hastada (\%16) pin etrafı yüzeysel enfeksiyon ile karşılaştık. Diğer serilerde bu oran $\% 4$ ile $\% 13$ arasında değişmektedir. $^{27,29}$ Kapandji grubunda herhangi bir yüzeyel enfeksiyon ile karşılaşmadık.

Kapandji yöntemiyle tedavi edilen grupta 2 tendon rüptürü (ekstensör pollisis longus) ile karşıllaştık, eksternal fiksatör grubunda tendon lezyonu ile karş1laşmadık. Tendon rüptürü sebebi kırık mı yoksa uygulanan tedavi yöntemi mi olduğunu tahmin etmek zordur. Milliez ve ark.'na ${ }^{17}$ göre intrafokal tellemeden sonra uygulanacak sistematik immobilizasyon tendon rüptür oranını azaltacaktır.

Nöroalgodistrofi eksternal fiksatörün önemli bir komplikasyonudur. Bazıları aşırı distraksiyonu bundan sorumlu tutmaktadır. Fakat nöroalgodistrofi teknik ne olursa olsun hemen her seride bulunmaktadır. Atkins ve ark., ${ }^{30}$ kapalı redüksiyon ve alçı ile tespit uyguladığı serisinde $\% 25$ nöroalgodistrofi bildirmektedir. Buna karşın Krukhaug ve ark. ${ }^{28}$ eksternal fiksatör kullanılan 75 hastalık bir seride hiçbir nöroalgodistrofi vakasına rastlamamıştır.

Sonuç olarak, çok sıklıkla gerektiği gibi önem verilmeyen radius distal uç kırığı, çok sık karşılaşılan kompleks bir lezyondur. Yıllar boyunca değişik tedavi yöntemleri önerilmiştir. İntrafokal telleme ve eksternal fiksatör en çok kullanılan tekniklerdir. Bazen gözden kaçırılan bazen de önem verilmeyen bazı kırıklar yanlış kaynama sonucu fonksiyon bozukluğu ile sonlanır.

Eksternal fiksatör, ligamantotaksis etkisiyle, iyi bir fragman dizilimine izin verir ancak redüksiyon, özellikle eklem içi kırıklarda, herzaman tatmin edici olmayabilir. Kapandji yöntemiyle intrafokal telleme dorsale ve radiale olan yer değiştirmeyi düzelttiği gibi erken mobilizasyona izin verir.

Her iki teknik ile elde edilen sonuçlar birbirine benzerdir. Kapandji yöntemiyle tedavi edilen hastalarda fonksiyonel geri kazanım daha çabuk olmaktadır. Eksternal fiksatör ile tedavi edilen hastalarda daha fazla komplikasyon görülmesine rağmen, sıklıkla yüzeysel enfeksiyon olan bu komplikasyonlar fonksiyonel sonuçlar üzerinde olumsuz etki yapmaz. Kapandji yöntemiyle daha az komplikasyon görülmesine rağmen, komplikasyonlar daha önemlidir ve fonksiyon üzerine kötü etki eder. Genel olarak konsolidasyon süresi 6 hafta kabul edilmesine rağmen 6 . 
haftadan sonra bile redüksiyonun kalitesinde azalma görülebiliyor. Bizce konsolidasyon süresi düşünülenden daha uzun sürmektedir. Acaba immobilizasyon süresinin biraz daha arttırılması veya tellerin çıkarılmasının geciktirilmesi gerekmez mi? Ayrıca, kemik grefti, önemli dorsal çok parçalanma olan kırıklarda radyolojik sonuçları iyileştirecek bir çözüm olabilir.

Etik komite onayı: Çalışmamız Brugmann Hastanesi Etik Kurulu tarafindan onayland1 (Tarih: 18/11/1997, Karar no: C.E.1997/36).

Çıkar çatışması: Yazarlar çıkar çatışması bildirmemişlerdir.

Yazar Katkıları: Fikir - G.R.U., M.V; Denetleme M.V.; Malzemeler - G.R.U., M.V.; Veri toplanması ve/vaya işlemesi - G.R.U., M.V., P.B.; Analiz ve/ veya yorum - G.R.U., M.V., P.B., P.P.; Yazıyı yazan - G.R.U.

Hakem değerlendirmesi: Dış bağımsız.

Ethics Commitee Approval: Our study was approved by the Brugmann Hospital Ethics Commitee (Date:18/11/1997, Decision no: C.E.1997/36)

Conflict of interest: No conflict of interest was declared by the authors.

Author Contributions: Concept - G.R.U., M.V; Supervision - M.V.; Materials - G.R.U., M.V.; Data Collection and/or Processing - G.R.U., M.V., P.B.; Analysis and/or Interpretation - G.R.U., M.V., P.B., P.P.; Writing - G.R.U.

Peer-review: Externally peer-reviewed

\section{KAYNAKLAR}

1. Pogue DJ, Viegas SF, Patterson RM, et al. Effects of distal radius fracture malunion on wrist joint mechanics. J Hand Surg Am. 1990;15(5):721-727.

2. Baumer A, McQueen MM. Fractures of the distal radius in low-demand elderly patients: closed reduction of no value in 53 of 60 wrists. Acta Orthop Scand. 2003;74(1):98-100.

3. Jupiter JB. Fractures of distal end of radius. J Bone Joint Surg Am. 1991;73(3):461-469.

4. Kapandji A. Ostéosynthèse par double embrochage intrafocal. Traitement fonctionnel des fractures non articulaires de l'extrémité inférieure du radius. Ann Chir. 1976;30(1112):903-908.

5. Slutsky DJ. External fixation of distal radius fractures. J Hand Surg Am. 2007;32:1624-37
6. Mirhamidi SM, Bayat FM. A prospective comparison between Kapandji and percutaneous extra-focal fixation in extraarticular distal radius fractures. Int J Clin Exp Med. 2013;6(2):133-139.

7. Trumble TE, Wagner W, Hanel DP, Vedder NB, Gilbert M. Intrafocal (Kapandji) pinning of distal radius fractures with and without external fixation. J Hand Surg. 1998;23(3): 381-394.

8. Kaempffe FA, Wheeler DR, Peimer CA, Hvisdak KS, Ceravolo J, Senall J. Severe fractures of the distal radius: effect of amount and duration of external fixator distraction on outcome. J Hand Surg. 1993;18(1):33-41.

9. Castaing J. Les fractures récentes de l'extrémité inférieure du radius chez l'adulte. Rev Chir Orthop. 1964;50:581-696.

10. Maffulli N, Fixsen JA. Painful hypertrophic non -union of the unlar styloid. J Hand Surg Br. 1990;15(3):355-357.

11. Tsukazaki T, Iwasaki K. Ulnar wrist pain after Colles' fracture. Acta Orthop Scand. 1993;64 (4):462-464.

12. Bisaccia M, Rinonapoli G, Bisaccia O. Articular fractures of distal radius: Comparison of treatment and clinical and radiological outcomes with volar plate versus Hoffmann bridging external fixator. Euromediterranean Biomedical Journal. 2017;12(6):23-28.

13. Delattre O, Saillant G, J Lemoine, Benazet JP, Roy-Camille R. Reduction and osteosynthesis with pin fixation of wrist fractures. A comparative study between Kapandji's and Py's techniques. Rev Chir Orthop. 1994;80(2):94107.

14. Docquier J, Soete P, Twahirwa J, Flament A. Kapandji's method of intrafocal nailing in Pouteau-Colles fractures. Acta Orthop Belg. 1982;48(5):794-810.

15. Vaughan PA, Lui SM, Harrington IJ. Treatment of unstable fractures of the distal radius by external fixation. J Bone Jt Surg Br. 1985;67 (3):385-389.

16. Cooney WP, Linscheid RL, Dobyns JH. External pin fixation for unstable Colles' fractures. J Bone Joint Surg Am. 1979;61 (6A):840-845.

17. Milliez PY, Auquit-Auckbur I, Thomine JM. Fixation externe des fractures comminutives du radius distal. Cahier d'enseignement de la SOFCOT. Expansion Scientifique 
Publications, Paris. 1998:169-176.

18. Leung KS, Shen WY, Tsang HK, Chiu HK, Leung PC, Hung LK. An effective treatment of comminuted fractures of the distal radius. J Hand Surg Am. 1990;15(1):11-17.

19. Edwards G. Intra-articular fractures of the distal part of the radius treated with the small AO external fixator. J Bone Joint Surg Am. 1991;73 (8):1241-1250.

20. Cooney WP, Dobyns JH, Linscheid RL. Complications of Colles' fractures. J Bone Joint Surg Am. 1980;62(4):613-619.

21. Jakim I, Pieterse HS, Sweet MBE. External fixation for intra-articular fractures of the distal radius. J Bone Joint Surg Br. 1991;73(2):302306.

22. Jupiter JB, Lipton H. The operative treatment of intraarticular fractures of the distal radius. Clin Orthop Relat Res. 1993;292:48-61.

23. Herrera M, Chapman CB, Roh M, Strauch RJ, Rosenwasser MP. Treatment of unstable distal radius fractures with cancellous allograft and external fixation. J Hand Surg Am. 1999;24 (6):1269-1278.

24. Saddiki R, Ohl X, Hemery X, Vitry F, Dehoux E, Harisboure A. Dorsally displaced distal radius fractures : comparative study of Py's and Kapandji's techniques. Orthop Traumatol Surg Res. 2012;98(1):61-67.

25. Neto AP, Lhamby FC. Fixation of fractures of the distal extremity of the radius using the modified Kapandji technique: Evaluation of the radiological results. Rev Bras Ortop. 2015;46 (4):368-373.

26. Shukla R, Jain RK, Sharma NK, Kumar R.
External fixation versus volar locking plate for displaced intra-articular distal radius fracture: a prospective randomized comparative study of the functional outcomes. J Orthop Traumatol. 2014;15(4):265-70.

27. Wilcke MK, Abbaszadegan H, Adolphson PY. Wrist function recovers more rapidly after volar locked plating than after external fixation but the outcomes are similar after 1 year. Acta Orthop. 2011;82(1):76-81.

28. Krukhaug Y, Ugland S, Lie SA, Hove LM. External fixation of fractures of the distal radius: a randomized comparison of the Hoffman compact II non-bridging fixator and the Dynawrist fixator in 75 patients followed for 1 year. Acta Orthop. 2009;80(1):104-108.

29. Chilakamary VK, Lakkireddy M, Koppolu KK, Rapur S. Osteosynthesis in distal radius fractures with conventional bridging external fixator; tips and tricks for getting them right. J Clin Diagn Res. 2016;10(1):RC05-8.

30. Atkins RM, Duckworth T, Kanis JA. Algodystrophy following Colles' fracture. J Hand Surg Br. 1989;14(2):161-164. 
Table 1. Olguların cinsiyete göre dağılımı.

\begin{tabular}{|l|c|c|c|}
\hline \multirow{2}{*}{ Cinsiyet } & \multicolumn{2}{|c|}{ Kullanılan teknik } & \multirow{2}{*}{ Toplam } \\
\cline { 2 - 3 } & Eksternal fiksatör & Kapandji & \\
\hline Erkek & 4 & 8 & 12 \\
\hline Kadın & 51 & 38 & 89 \\
\hline Toplam & 55 & 46 & 101 \\
\hline
\end{tabular}


Tablo 2. 6. ay sonunda kullanılan tekniğe göre hareket açıklık derecesi.

\begin{tabular}{|l|c|c|c|c|}
\hline & \multicolumn{4}{|c|}{ 6.ay } \\
\hline & \multicolumn{2}{|c|}{ Eksternal fiksatör } & \multicolumn{2}{c|}{ Kapandji } \\
\hline Fleksiyon & Opere taraf & Karşı taraf & Opere taraf & Karşı taraf \\
\hline Ekstansiyon & $53^{\circ}$ & $62^{\circ}$ & $57^{\circ}$ & $63^{\circ}$ \\
\hline Ulnar deviasyon & $54^{\circ}$ & $64^{\circ}$ & $59^{\circ}$ & $66^{\circ}$ \\
\hline Radial deviasyon & $29^{\circ}$ & $36^{\circ}$ & $31^{\circ}$ & $36^{\circ}$ \\
\hline
\end{tabular}


Tablo 3. 6. Ay sonunda kullanılan tekniğe göre elde edilen radyolojik .

\begin{tabular}{|l|c|c|c|}
\hline \multirow{2}{*}{} & \multicolumn{3}{|c|}{ 6. ay } \\
\cline { 2 - 4 } & $\begin{array}{c}\text { Radial inklinasyon } \\
\text { (derece) }\end{array}$ & $\begin{array}{c}\text { Palmar tilt } \\
\text { (derece) }\end{array}$ & $\begin{array}{c}\text { Radioulnar indeks } \\
\text { (mm) }\end{array}$ \\
\hline Eksternal fiksatör & $21^{\circ}$ & $3,5^{\circ}$ & 1,4 \\
\hline Kapandji & $20^{\circ}$ & $5^{\circ}$ & 1,9 \\
\hline
\end{tabular}


Tablo 4. Eksternal fiksatör ve kapandji gruplarında eklem içi kırık bulunan hastaların (Frykman ve Older kalsifikasyonuna göre) sınıflandırılması.

\begin{tabular}{|c|c|c|c|}
\hline & Frykman & Frykman & Older-Tip 4 \\
\hline \multirow{4}{*}{ Eksternal fiksatör tekniği kullanılan hasta grubu } & Tip 3 & 2 & \multirow{4}{*}{11} \\
\hline & Tip 4 & 6 & \\
\hline & Tip 7 & - & \\
\hline & Tip 8 & 3 & \\
\hline \multirow{4}{*}{ Kapandji tekniği kullanılan hasta grubu } & Tip 3 & 4 & \multirow{4}{*}{16} \\
\hline & Tip 4 & 6 & \\
\hline & Tip 7 & 2 & \\
\hline & Tip 8 & 4 & \\
\hline
\end{tabular}

